\title{
Managing the Psychology of Health Care: What it means and what it is worth
}

\author{
Ilan Shahin*
}

\section{BACKGROUND}

Health care is perhaps the most complicated of services. While most services in the business world are challenged by the diversity of clients and variability in their needs, health care must face this challenge with tremendous pressure from other factors. On the one hand, the stakes are extremely high, and the demand for excellence is unmatched by those placed on other service providers. On the other hand, the whole activity takes place not only in the tangible world of wards and beds, but also in the abstract world of psychological and sociological forces that guide all stakeholders, from those holding the scalpel to those holding the chequebook.

While every issue in health care has its own shadow of debate and controversy, there are certainly moments of ephemeral consensus. The role of the patient in clinical decision making has been revisited along with the social and environmental changes in Western society over the past century. These include the acceleration of information exchange, increased awareness of rights and a steady erosion of physicians' perceived omnipotence, partly a result of the two previous developments. What we have today is the Partnership model, an acceptable model of the patientprovider relationship, whereby the patient is not a passive recipient of a series of health-related procedures, but rather an active participant who holds the final word on clinical decisions.

This arrangement raises some very interesting questions. The first wave is superficial, asking what the evidence is for it, against it, and what we can expect from this model from the perspective of patients and

*To whom correspondence should be addressed:

Ilan Shahin

5378 St. Urbain

Montreal, Quebec

H2T 2X1

ilan.shahin@gmail.com providers. The second wave asks about the hidden dynamics. Is an increased role for a patient really a dilution of expertise? Regardless of the answer, what happens to this current model in practice? Do the heightened emotional states and psychological distortions affect the patient's view of the situation to the point where they may not be acting in their best interests? This introduces the ethical question of determining best interests and delegating the authority to pursue them. With all these issues to be sorted out, how can health care managers plan to remove the impurities from the patient-provider relationship to optimize health outcomes?

\section{PATIENT EMPOWERMENT}

The term "patient empowerment" has been described by the World Health Organization as "a process through which people gain greater control over decisions and actions affecting their health" (1). Considering that health is a function of a multitude of variables and factors, this remains vague. For the purposes of this paper on clinical decision-making, empowerment can be understood by its primary function: to uphold the values and principles underlying declarations of patients' rights.

Patient Rights

In 1994, the WHO issued a declaration of patients' rights, and in 2002, the Active Citizen Network proposed a European Charter of Patients' Rights (2)(3). The most pertinent ones related to the patient's role in clinical decision making are as follows:

- Right to information, which includes personal as well as biomedical information, both of which should form the basis of any sound decision-making.

- Right to free choice between different treatment options.

Although these rights cannot be refuted, they must be exercised with caution in some particular contexts in 
order to avoid harm to the patients. Some examples of this will be discussed shortly.

\section{Access to information}

The big enabler of patient empowerment has been the ease with which patients can access and understand medical information. The biggest leap in the availability of information has come with the internet. Websites directed at patients such as webmd.com and familydoctor.org have shattered the health professional's monopoly on the distribution of information and corroded their power. While the knowledge of a competent physician will never be surpassed by that of the most avid reader of WebMD, informed patients have changed the dynamics of healthcare. A patient now has a basis for discussion, and with discussion comes doubt, challenge and in some cases, near-autonomous care on the part of the patient. The physician's aura of omnipotence has faded, or even, in some cases, disappeared, and new models of patientphysician relationship have arisen.

\section{PATIENT-HEALTH PROFESSIONALS INTERACTION MODELS}

The generic process of health care has several steps, beginning with detecting a problem or symptoms, continuing with information gathering, diagnosis, treatment and monitoring. Some of these steps involve decisions, the most significant one being the evaluation and selection of treatment options. There are six general models for health care delivery with defined roles for both the patient and health care provider in each step of the health care process (Table 1) (4). The two most extreme models are the Autonomous model and the Unilateral health care provider (HCP) model. The latter is likely rare in its pure form, and violates the basic principles that underlie patient-centered care. The more practical version of the Unilateral HCP model is the Paternalistic model, in which the most significant feature is that the chosen treatment is selected by the HCP.

The Partnership model is the intermediate between the two ends of the spectrum and is the one that seems most reasonable. In this model, every step is carried out with cooperation between the patient and the HCP. This model allows for several desirable practices to be put in place:

- The care process incorporates the knowledge and professionalism of HCPs

- The patient's involvement in gathering information about the condition and treatment options introduces a second competent voice to the discussion on their health

- The patient's involvement in the generation and selection of treatment options requires a level of knowledge shown to improve adherence and outcomes (4)

- The communication required by the Partnership model has been shown to improve patient satisfaction (5)

- The patient's values regarding health are strong decision inputs

From a theoretical perspective, it seems that this partnership model is ideal, based on the notion that a patient should be informed of their health situation with the HCP as only one of multiple sources and that they should be participants in the clinical decision regarding treatment, a decision made with respect to their values.

\begin{tabular}{|c|c|c|c|c|c|c|}
\hline Activities & $\begin{array}{c}\text { (A) } \\
\text { Autonomous } \\
\text { patient }\end{array}$ & $\begin{array}{l}\text { (B) } \\
\text { Autonomous health } \\
\text { care system patient }\end{array}$ & $\begin{array}{c}(\mathrm{O}) \\
\text { Partnership }\end{array}$ & $\begin{array}{c}\text { (D) } \\
\text { Propose - } \\
\text { Dispose Model }\end{array}$ & $\begin{array}{c}\text { (E) } \\
\text { Paternalistic } \\
\text { model }\end{array}$ & $\begin{array}{c}(\mathrm{F}) \\
\text { Unilateral } \\
\text { HOP model }\end{array}$ \\
\hline HEALTHCAREPROMDER(HCP) ROF & None & Prescription writer & Partner & Expert & Authority & «God » \\
\hline $\begin{array}{l}\text { (1) Poblem detection } \\
\text { (signs \& symptoms) }\end{array}$ & Patient & Patient & Patient + HOP & Patient + HOP & Patient + HOP & $\mathrm{HCP}$ \\
\hline $\begin{array}{l}\text { (2) Additional patient information } \\
\text { required for diagnosis } \\
\end{array}$ & Patient & Patient & $\begin{array}{c}\text { Patient + HOP } \\
\text { (e.g., medical record) }\end{array}$ & $\begin{array}{c}\text { Patient + HCP } \\
\text { (e.g., medical record) }\end{array}$ & $\begin{array}{c}\text { Patient + HCP } \\
\text { (e.g., medical record) }\end{array}$ & $\mathrm{HOP}$ \\
\hline (3) Diagnosis \& Prognosis & Patient & Patient & Patient + HOP & $\mathrm{HOP}$ & $\mathrm{HCP}$ & $\mathrm{HCP}$ \\
\hline (4) Define health goals & Patient & Patient & Patient + HCP & $\mathrm{HCP}$ & $\mathrm{HCP}$ & $\mathrm{HCP}$ \\
\hline (5) Generate treatment options & Patient & Patient & Patient + HOP & $\mathrm{HOP}$ & $\mathrm{HOP}$ & $\mathrm{HOP}$ \\
\hline $\begin{array}{l}\text { (6) Generate general information } \\
\text { about options } \\
\end{array}$ & Patient & Patient & Patient + HOP & $\mathrm{HOP}$ & $\mathrm{HCP}$ & $\mathrm{HOP}$ \\
\hline $\begin{array}{l}\text { (7) Generate patient information needed } \\
\text { to assess option suitability for patient } \\
\text { (contraindications, etc.) }\end{array}$ & Patient & Patient & Patient + HOP & Patient + HOP & HOP + Patient & $\mathrm{HOP}$ \\
\hline (8) Evaluate options & Patient & Patient & Patient + HOP & $\mathrm{HOP}$ & $\mathrm{HCP}$ & $\mathrm{HOP}$ \\
\hline (9) Decide on treatment option & Patient & Patient & Patient + HOP & Patient & $\mathrm{HCP}$ & $\mathrm{HOP}$ \\
\hline (10) Implement treatment & Patient & Patient & Patient + HCP & Patient & Patient & $\mathrm{HCP}$ \\
\hline (11) Monitor and evaluate & Patient & Patient & Patient + HCP & Patient + HOP & $\mathrm{HOP}$ & $\mathrm{HCP}$ \\
\hline
\end{tabular}

Table 1.Models of patient-physician treatment involvement (4; reproduced with permission) 


\section{HEALTH OUTCOMES AND PATIENT EMPOWERMENT IN THE PARTNERSHIP MODEL}

In healthcare, a process, strategy or practice is only as good as the health outcomes associated with its implementation. In this case, there are many studies that confirm the value of some element or form of a partnership model.

\section{Communication}

In a study sponsored by the Austrian Ministry of Health, outcomes were compared for patients undergoing cardiac surgery before and after HCPs underwent communication training for admissions, presurgery and discharge discussions (5). The differences are significant. Patients in the intervention group were discharged 1.1 days earlier, were transferred quicker to less intense treatment, and experienced an $11 \%$ increase in overall satisfaction, as well as improvement in several communication and pain-based measures of satisfaction. These outcomes can be attributed to the enhanced communication similar to the patient-centric principle that motivates the partnership model.

\section{Information}

Smith et al carried out a cluster randomized trial testing the effectiveness of mailed communications in increasing adherence to beta-blocker therapy in patients with recent myocardial infarctions (6). Patients received two mailings spaced two months apart, containing similar information. Written in lay language after extensive consultations with patient focus groups, the mailings addressed the importance of beta-blocker therapy, the risks of non-compliance and handling of adverse effects and information on alternative and complementary therapies such as statins, ACEinhibitors and aspirin. Defining adherence as a percentof-days covered greater than $80,17 \%$ more patients were adherent in the intervention group than the controlled group. The intervention here includes information that should be part of a healthy HCPpatient relationship based on the partnership model.

\section{HCP disposition}

The Centre for Studies in Family Medicine at the University of Western Ontario carried out a study whereby medical consultations were taped and assessed by a research assistant as well as patient post-encounter survey for various measures of patient-centeredness (7). Patients were followed up for two months and observed for health outcomes as well as consumption of health care services. Patients perceiving that a consultation was patient-centered were less likely to receive diagnostic tests ( $14.6 \%$ vs. $24.3 \%)$ and be referred ( $8 \%$ vs. $16 \%$ ) in the following two months than patients who did not perceive that the consultation was patientcentered. Differences were even more pronounced with respect to patients reporting that they found common ground with their physician, defined as "when the physician clearly described the problem and the management plan, answered questions about them, and discussed and agreed on them with the patient". Of patients perceiving that they found common ground with their physician, only $4.1 \%$ received diagnostic tests and $6.1 \%$ received referrals in the next two months compared to $25.4 \%$ receiving diagnostic tests and $14.9 \%$ being referred for patients who did not perceive that common ground was established. Perceived patient-centeredness was associated with lower postencounter levels of discomfort and concern using a visual analog scale and the mental health dimension of the medical outcomes study short form 36 surveys. Perceived finding of common ground was associated with a lower post-encounter level of concern.

This study shows that the interaction between patients and their physician is very influential towards patients' health-related anxieties as well as consumption of health services. The more sympathetic, open communication between physicians and patients favored by the partnership model is a powerful force in health care delivery.

With this evidence from research into physicianpatient communication, information transfer and relationship-building, it is clear that there are benefits to be had form implementing the Partnership model as measured by health outcomes.

\section{THE DOWNSIDE TO PATIENT EMPOWERMENT}

While patient-empowerment within the context of a well-executed Partnership model has clear benefits, there are also downsides which may surface in cases of both partial and full implementation, pertaining specifically to increased costs, reduced health outcomes and more inefficiency in the delivery of care.

Direct to consumer advertising (DTCA) for pharmaceuticals is a form of patient empowerment and is consistent with the Partnership model because it informs patients regarding their condition and treatment options. The DTCA practice is controversial because it may lead to overuse even though it prevents underuse. A study published by Kravitz et al. tested the prescription rate for patients diagnosed with depression or adjustment disorder who asked their HCP either for a specific drug by brand name or generic name, or did not ask for a specific drug treatment (8). Prescription rates for patients with depression were $53 \%, 76 \%$ and $31 \%$ respectively, and $55 \%, 39 \%$ and $10 \%$ for patients with 
adjustment disorder. The fact that patients who did not ask for a specific drug were given pharmacological treatment about half the time, or less, than patients who asked for a drug by name is an illustration of the influence of patient empowerment. This power is not necessarily beneficial, as it could be argued that the results of this study are evidence of patient empowerment leading to unnecessary treatment, which can lead to decreased healthcare outcomes and increased costs.

The partnership model is rarely implemented in its ideal form. A study carried out by Stevenson et al. in the UK that recorded conversations between physicians and patients found that in most cases, communication was poor and patient-centered bedside manner, inadequate (9). This lead the researchers to conclude that they "found little evidence that doctors and patients both participate in the [partnership model]" (9).

The attitude of physicians seems to be the main factor in the low use of the partnership model, as evidenced in the oft-quoted article by Rebecca Say and Richard Thompson (10). What they found was that doctors had a hard time handling the heterogeneity of patients' expectations with regards to the level of involvement between the two parties. In some cases, physicians reported that the discussion of treatment options lead to anxiety in patients if they felt that their physician was unsure of the proper course of treatment. This discussion is however central to the partnership model and should be modified if it is causing more harm than good. Another difficult scenario occurs when doctors must respond to information obtained from the internet, either or low quality or misinterpreted by the patients. While well-executed communication and education interventions led to benefits, poor execution of those same endeavors leads to frustration and potential inefficiency. These issues have discouraged some physicians and patients from seeking the ideal Partnership model. However, these same issues should be addressed by health managers in order to exact the benefits of the interaction model. As physicians and patients become more accustomed to the partnership model and the expectations it holds for each party, the problems cited in the report should be less prevalent and less prohibitive as barriers to good care.

\section{THE VERDICT SO FAR}

The Partnership model has won favor in theory among academics and policy-makers. Studies with and without intervention components have shown that there are many benefits to be had from a well-executed partnership model, be it in the form of reduced costs, improved health outcomes or improved satisfaction. It has also been shown that such a model may introduce challenges such as over treatment, decreased timeliness, increased costs, and frustration on the part of both physicians and patients. The Partnership model is still in its developmental stages in practice, but the consensus is that it is the most appropriate way to proceed going forward.

\section{WHAT MAKES THE PARTNERSHIP MODEL BETTER?}

When comparing the Partnership model to its alternatives that differ by patient-HCP dynamics, it is reasonable to conclude that improvements in health outcomes are rooted in those dynamics. These can be direct in that improved communication leads to better diagnoses and the selection of more appropriate treatment options. They can also be indirect in that the dynamics enable the emotive care associated with improved patient satisfaction and clinical outcomes. By either route, the effect is primarily psychological. Health managers should want to know where they can harness psychology to their advantage, and where a poor understanding of patient psychology will ultimately lead to worse health outcomes and a less satisfying experience for both patient and HCP.

\section{PSYCHOLOGICAL DETERMINANTS IN PATIENT BEHAVIOUR}

A patient is constantly making decisions with regards to care. It begins with how they interpret symptoms such as whether that persistent pain is circumstantial or worthy of medical attention. In deciding treatment options, a patient makes the most explicit choice based on information they have gathered. Finally, there is the treatment phase where a patient must be committed to treatment. This means that there are three characteristic situations where a patient must make decisions: observation of state of health before presenting to a $\mathrm{HCP}$, discussion and decision during the medical interview, and the treatment phase.

\section{Observation}

During the observation phase, the patient passively observes their health, noting any points of concern, monitoring them and choosing between seeking medical attention or not. The first patient decision relates to symptom observation. Cognitive psychology defines a confirmation bias as "a tendency to search for information that confirms one's preconceptions" (11). A hypochondriac patient is subject to this bias when they interpret benign symptoms to be caused by a serious disease. Working in the other direction, another patient may look for days when they feel good to confirm that they are healthy. This bias towards desirable outcomes is consistent with the desirability bias, a form of 
"wishful thinking" (12). Another form of bias is the denial bias. A study by Phelan et al. showed that there was "widespread denial" among women who were late to seek medical attention for breast cancer (13). While these psychological phenomena are challenges at the micro level, they are also challenges that must be met at the population level. Much of the observation takes place with no physician involvement whatsoever. This is a growing problem in countries like Canada where it is estimated that $15 \%$ of Canadians do not have a general practitioner (14). Because this observation phase is often free of physician involvement, these biases must not only be confronted during face-to-face contact with HCPs, but at every point in the interface between the health care body and the general public.

To counter these biases, health managers must focus on communication that manipulates another bias of cognitive psychology, known as the framing bias. A frame is defined as "a psychological device that offers a perspective and manipulates salience in order to influence subsequent judgment" (15). In a landmark study by Beth Meyerowitz and Shelly Cheiken, it was shown that framing - manipulated through language significantly affected the intentions of young women to perform breast self-examinations (BSE) (16). They distributed three different pamphlets about BSE, lossframe, gain-frame and no-arguments, where the frame type is defined by whether the negative consequences of not performing BSEs (loss frame), the positive benefits of performing BSEs (gain frame) or neither (noarguments) were stressed. After four months, $57 \%$ of subjects in the loss-frame pool increased the frequency of BSE compared to that prior to reading the pamphlet, while $38 \%$ and $39 \%$ reported the same for the gainframe and no-arguments pamphlet. This shows that health managers must be especially mindful of the psychological implications of the conversations they are having with the patients, at both the micro and macro levels.

\section{Medical Interview}

This clinical phase involves two components. In the first, a patient and their HCPs discuss the medical elements of the condition, as well as treatment options and risks. This phase can be considered one of information gathering in essence and similar to the observation phase, though ideally it is less autonomous as it is a process done in partnership with the guidance of an HCP. The same cast of biases can apply here too, as a patient may have confirmation, desirability, and other similar biases that will direct their focus to and from certain bits of information.

The decision-making process can be influenced by several biases.
Focusing Effect - In decision making, it is defined as "not taking into account alternatives to an option that has been initially proposed or generated" (17). With increased access to information, patients may be more inclined to choose a treatment on their own prior to discussion with an HCP. This is dangerous in that the option may not be the best option for them, but is favored because of this bias. While not deterministic, "this initial focus on a given option may also make the subsequent retrieval of information about known alternatives more difficult" (18). To counter this, the exploration of alternative options must be facilitated under the guidance of HCPs. This will encourage both an understanding and consideration of alternative options where a focusing effect in a patient-driven education process would discourage both.

Loss Aversion - This concept is part of prospect theory, put forward by Kahneman and Tversky in 1979 which revisited the traditional theory of utilitarianism (19). It says that people are more motivated to avoid losses than pursue equal gains. In the context of health, this could be present when considering serious risks from surgery. It may explain why so many men with prostate cancer initially choose "watchful waiting" to avoid associated risks even though $50 \%$ of them will proceed to treatment within three years due to disease progression or anxiety (20). This is problematic, as it can delay treatment where the outcomes are timesensitive. It is difficult to counteract this phenomenon $a$ priori because the neutrality of an HCP as a counselor is likely compromised, presenting an ethical issue. Instead, HCPs should be trained to recognize lossaversion stemming from emotionally-charged thoughts and steer the patients towards a more balanced view, especially where the patient may be misinformed about certain risks.

Availability Heuristic - Another theory by Tversky and Kahneman proposes that the availability heuristic is employed when a person "estimates frequency or probability by the ease with which instances or associations could be brought to mind" (21). Patients' conceptions of illness are generally most influenced by experiences of family and their immediate circle. It is therefore based on a very small, statistically insignificant yet emotionally and psychologically charged sample. Patients may draw on what they hear anecdotally to generate their own probability distribution of outcomes that is more vivid and therefore likely dominant over the outcome probabilities accepted by the medical community.

As with loss aversion, it remains the responsibility of HCPs to notice these heuristics and manage them. This takes time and will likely cause tensions in the patientHCP relationship, but it is nonetheless a necessary 
component of good patient-centered health care.

\section{Treatment}

The compliance of patients to the treatments prescribed is an often-discussed topic; it is unfortunately often very low. In the case of many infectious diseases, such as tuberculosis, patients are more prone to being non-compliant once they reach the asymptomatic stage, as they mistakenly equate well being with cure (22). While this non-compliance is brought about by poor education regarding the disease and its treatment timeline, it is made worse by the fact that patients may deny that they are sick or be overconfident regarding their health. These are HCPindependent processes, and are a good argument for increasing the frequency of HCP-patient interactions, discussions about patients' concerns and beliefs, and patient education. For treatments that take place over extended periods of time, particularly those that include asymptomatic phases, patients must be closely monitored to facilitate discussion with HCPs. Unfortunately, many of these thoughts and emotions are tied to external perceptions and stigma, meaning that the scope of the education efforts is widened from being patient-specific to community-wide.

\section{PATIENT DECISION AIDS: ON THE PSYCHOLOGICAL FRONT LINES}

For the most part, all these biases and psychological challenges to good health care decision-making and outcomes share two characteristics. Their genesis occurs outside the health care system, and they are information-based. Therefore the antidote, though not deterministic, must address those two concerns.

In her editorial published in Evidence Based Medicine in 2001, Annette O'Connor gives an overview of what a patient decision aid (PDA) is, what it does, as well as the characteristics of the best ones (23). PDAs have the following elements:

1. Information regarding the patient's condition: Coming from a reputable source, PDAs should inform patients of the medical background, treatment options and risks, as well as make reference to other credible sources of information.

2. Values classification: Using questionnaires to guide patients to a resolution on their values and health-related priorities simplifies the experience for patients and HCPs.

3. Examples of other patients: This has a therapeutic effect when patients are being expected to make a very important decision regarding their health. 4. A guide to shared decision making: Some patients may be intimidated by the medical environment and not exercise their full patient rights as partners in the delivery of their care.

These aids are very patient-centric, and truly abide by the principles of the Partnership model, patient rights and patient education. With the ubiquity of the internet, PDAs are easily distributed and shared among institutions. They are clearly relevant to this paper's discussion in that they are both information based and delivered under the guidance of HCPs. PDAs are an appropriate tool to counter the psychological biases that challenge health care outcomes. Education seems to be the universal antidote, but it is a specific type of education - HCP endorsed and guided - that will truly help patients. The effects of the emotions-driven availability heuristic are mitigated by a sound discussion on risks and outcomes, as well as the examples of other patients. The patient framework as a whole is guided by their values. It is important that these be brought about and discussed with the HCP, as one of the motivations for patient-centric care and the Partnership model is that patients' values be respected.

It is easy to suggest that all health providers should begin to distribute PDAs, focus on patient education and train their HCP to navigate the psychological labyrinth of a patient's mind. It is far harder to predict how great an effect it will have on health outcomes.

\section{PUTTING THE PSYCHOLOGICAL DISCUSSION INTO PERSPECTIVE}

The patient-centered Partnership model has been shown to be beneficial in many cases.. It may be hard to believe that just talking to Austrian cardiac surgery patients should lessen their pain, increase their recovery speed and discharge them over a day sooner from the hospital (5). Considered from a financial perspective, this leads to a significant reduction in costs as the patient flow rate increases, effectively increasing capacity through conversation. Even a simple thing such as loss-frame pamphlets has been shown to increase the frequency with which women perform BSEs $20 \%$ more than gain-frame and no-arguments pamphlets do. This leads to earlier detection of breast cancer, and better health outcomes.

One can extrapolate these findings to other cancers, procedures and interactions with the health system to guess the magnitude of improvement. One also has to wonder how much improvement can be made if a systematic effort was launched, aimed at harnessing the psychological forces that drive these improvements in health outcomes. While estimating the impacts would require an amount of research that goes beyond the scope of this paper, it would not be surprising if it were of the same magnitude as medical errors, now the focus of health managers worldwide. The Canadian Institute for Health Information estimated that medical errors kill 
up to 24,000 Canadians each year (24). The Institute of Medicine's seminal report titled "To Err is Human: Building a Safer Health System" estimated that this figure lies between 44,000 and 98,000 in the United States, and that the cost associated with medical error is 17-29 billion dollars (25). These figures were once seen as a revelation. It is therefore plausible that mismanagement of health care psychology comes at a human and financial cost similar in magnitude to that of medical error that was once unknown as well. Health managers now understand the cost of process neglect, of not being vigilant in what they do. Now they need to understand the cost of neglecting the psychological side of health care delivery, not only in avoiding harm, but in enhancing care above expectations through what they say and how they say it.

If proper management of the psychology of health care can have such effects, the benefits will far exceed the costs of the implementation and management. This must be explicitly addressed by the health care management community.

\section{CONCLUSION}

Changes in the principles that guide health care, as well as the technological and sociological environment surrounding it have lead to a patient-centered care model, called the Partnership model. In this model, all steps of the care pathway are done by patients and HCP in partnership, particularly when it comes to therapeutic decisions. This model necessitates that a patient be well-informed and clear about their values and priorities, and that HCPs are able to serve that need. There is much evidence to show that this model is indeed a positive intervention for health outcomes. The analysis of the evidence points to psychology as a driving force. This paper outlined some of the psychological biases that may act against health interests and presented strategies to mitigate those risks, led primarily through patient decision aids. PDAs embody the informational, value guidance and support needs of patients to be positive contributors and active participants in their health. Properly executing these strategies could undo harm and unleash the positive benefits of this very unconventional force in health care. The magnitude of significance may be in the order of that of medical error.

This paper has focused on the patient. However, HCPs are equally human, and equally susceptible to psychological biases, though they can be educated to be self-aware of those biases in order to provide better care for their patients. Health care managers must be mindful of these forces in patients, their professional staff, and even support staff. Instilling a psychologically positive environment cannot be an effort focused on one stakeholder in health care, but on all stakeholders.

Just as a house is as good as its design, foundation and materials, health care is as good as its own homologues to those elements: the processes put in place, the biomedical knowledge, and the social and psychological forces that contribute and influence each interaction. A second look at the Partnership model and the evidence surrounding it will show how much of a role psychology plays. With minds come emotions, biases and moments of cloudy thoughts. The big challenge for health care providers will be to manage these as threats. The biggest opportunity will be to harness these as forces that can be manipulated to achieve improved health outcomes for all.

\section{REFERENCES}

1. World Health Organization (WHO) - Division of Health Promotion, Education and Communications. Health Promotion Glossary. 1998:1-36. http://www.who.int/healthpromotion/ about/HPR\%20Glossary\%201998.pdf

2. WHO. Principles of the Rights of Patients in Europe: A common framework. 1994 Jun:1-15. http://www.who.int/genomics/ public/eu_declaration1994.pdf

3. Active Citizen Network. European Charter of Patients' Rights. 2002 Nov:1-12. http://www.activecitizenship.net/index2.php? option $=$ com_docman\&task $=$ doc_view\&gid $=19 \&$ Itemid $=86$

4. Angelmar R, Berman P. Patient Empowerment and Efficient Health Outcomes. 2007 Jan:139-162. http://www.sustainhealthcare.org/Report_3.pdf

5. Trummer U, Mueller U, Nowak P, Stidl T, Pelikan J. Does physician-patient communication that aims at empowering patients improve clinical outcome? a case study. Patient Education and Counselling. 2006 May;61(2):299-306.

6. Smith DH, Kramer JM, Perrin N, Platt R, Roblin DW, Lane K, Goodman M, Nelson WW, Yang X, Soumerai SB. A randomized trial of direct-to-patient communication to enhance adherence to beta-blocker therapy following myocardial infarction. Archives of Internal Medicine. 2008 Mar 10;168(5):477-83.

7. Stewart MA, Brown JB, Donner A, McWhinney IR, Oates J, Weston WW, Jordan J. The impact of patient-centered care on outcomes. The Journal of Family Practice. 2000 Sept;49(9):796804.

8. Kravitz RL, Epstein RM, Feldman MD, Franz CE, Azari R, Wilkes MS, Hinton L, Franks P. (2005). Influence of Patients' Requests for Direct-to-Consumer Advertised Antidepressants: An Randomized Controlled Trial. JAMA. 2005 Apr 27;293(16):1995-2002.

9. Stevenson FA, Barry CA, Britten N, Barber N, Bradley CP. Doctor-Patient Communication About Drugs: The Evidence for Shared Decision Making. Social Science \& Medicine. 2000 Mar;50(6):829-840.

10. Say R, Thompson R. The importance of patient preferences in treatment decisions-challenges for doctors. BMJ. 2003 Sept 6;327:542-5.

11. Myers, D. Social Psychology. 7th ed. New York: McGraw-Hill; 2001.

12. Krizan Z, Windschitl P. The Influence of Outcome Desirability on Optimism, Psychological Bulletin. 2007;133(1):95-121.

13. Phelan M, Dobbs M, David AS. "I thought it would go away": patient denial in breast cancer. Journal of the Royal Society of Medicine. 1992;85:206-207.

14. Statistics Canada. Canadian Community Health Survey. The 
Daily. 2008 Jun 18. http://www.statcan.ca/Daily/ English/080618/d080618a.htm

15. Workingpsychology.com. Los Angeles: Kelton Rhoads, PhD.; c1997-2004. [cited on 2007 Apr 7] Framing IV; [about 2 screens]. Available from: http://www.workingpsychology.com /whatfram.html.

16. Meyerowitz B, Chaiken S. The Effect of Message Framing on Breast Self-Examination Attitudes, Intentions, and Behavior. Journal of Personality and Social Psychology. 1987 Mar;52(3):500-510.

17. Del Missier F, Ferrante D, Costantini E. (2006) Focusing Effects in Predecisional Information Acquisition, Acta Psychologica. 2007 Jun;125(2):155-174.

18. Sanbonmatsu DM, Posavac SS, Kardes FR, Mantel SP. Selective hypothesis testing. Psychonomic Bulletin \& Review. 1998;5(2):197-220.

19. Kahneman D, Tversky A. Prospect Theory: An Analysis of Decision under Risk. Econometrica. 1979 Mar;47(2):263-291.
20. Klein, E. Treatment for Early Prostate Cancer, Uptodate.com. 2006.

21. Tverksy A, Kahneman D. Availability: A heuristic for judging frequency and probability. Cognitive Psychology. 1973;4:207232.

22. Jaiswal A, Singh V, Odgen JA, Porter JDH, Sharma PP, Sarin R, Arora VK, Jain RC. Adherence to tuberculosis treatment: lessons from the urban setting of Delhi, India. Tropical Medicine and International Health. 2003 July;8(7):625-633.

23. O'Connor A. Using patient decision aids to promote evidencebased decision making, Evidence-Based Medicine. 2001;6:100102 .

24. Canadian Institute for Health Information. Health Care in Canada 2004. Ottawa (Canada): Canadian Institute for Health Information; 2004.

25. Institute of Medicine. To Err is Human: Building a Safer Health System. 1st ed. Kohn LT, Corrigan JM, Donaldson MS, editors. Washington D.C. (USA): National Academy Press; 2000.

Ilan Shahin (B.Sc. 2006, MD-CM 2011, MBA 2011) is a graduate of McGill University's Biology and Mathematics faculty program and holds a Philosphy minor. He is interested in health policy and management, particularly the psychological and emotional factors pertaining to health care as well as their effects on health outcomes and system performance. 